\title{
TELEMATICS BUSINESS AND MANAGEMENT IN BAHRAIN MARKET
}

\author{
Marwan Rajeh Hussain ${ }^{1}$, Abduljalil Zainal', Wael Mohamed Elmedany ${ }^{3}$, \\ Mohamed Waleed Fakhr
}

\author{
${ }^{1}$ Telematics Department (consultant), Spatial Technology Solutions (STS), University of Bahrain \\ P.O Box 32038, Manama, Kingdom of Bahrain \\ E-mail:marwan.rajeh@sts-int.net \\ ${ }^{2}$ CEO, Spatial Technology Solutions (STS), University of Bahrain \\ Manama, Kingdom of Bahrain \\ E-mail: abduljalil.zainal@sts-int.net \\ ${ }^{3}$ Computer Engineering Department, University of Bahrain \\ P.O. Box 32038, Manama, Kingdom of Bahrain \\ E-mail:welmedany@uob.edu.bh \\ ${ }^{4}$ Electronic Engineering Department, University of Bahrain \\ Manama, Kingdom of Bahrain \\ E-mail:waleedfakhr@yahoo.com
}

\begin{abstract}
The aim of this paper is to present and discuss issues related to the telematics business and management in Bahrain. Telematics is a part of Information and Communication Technologies (ICT), which plays a major role in the economic development of countries. Telematics applications are becoming increasingly important in modern transportation to increase reliability, safety and security of both vehicles and drivers. There are many applications for telematics; some of these applications are telematics for educations, telematics for health, and vehicle telematics. One of the most important applications of telematics is vehicle telematics, which includes vehicle tracking, fleet management, container tracking, trail tracking. In this paper we are focusing on vehicle telematics business and management in Bahrain market.
\end{abstract}

Keywords: Telematics, ICT, Vehicle Telematics, GPS, GSM, GPRS, navigation, fleet management

\section{Introduction}

Information and Communication Technologies (ICTs) denote a wide range of services, applications and technologies, using various types of hardware and software, often running over telecommunication networks. The importance of ICTs is the enabling function in facilitating enhanced access to information and communication across large distances [1]. One of the most important components of ICT is the telematics, which in turns includes many other components and devices that are used in different telecommunication applications [2].

Telematics is defined as an integrated use of telecommunications and informatics; it is about the sending, receiving and storing information via telecommunication devices (GSM/GPRS) along with controlling of remote objects [3], [4], [5]. Telematics applications are becoming increasingly important for auto insurers in numerous countries as they seek to control claim costs, enhance pricing sophistication, improve profitability, and differentiate their policyholder products and services [3].

Telematics nowadays plays a major role in the economic development of countries. It includes but not limited to Global Positioning System (GPS) technology integrated with computers and mobile communications technology in automotive navigation systems [6], [7]. With the enormous market potential of the telematics industry and the rapid development of information technology, automotive telematics has attracted considerable attention for mobile computing and Intelligent Transport Systems (ITSs) [8]. The telematics services, includes, navigation services, remote diagnostics, emergency calls and more [9]. There are many telematics applications examples around the world, many publications for telematics applications and developments of telematics in different courtiers are already online, as an example is study of the telematics industry in Korea and China [10].

In Bahrain, like in the other Gulf Co-operation Council (GCC) Countries, there is an urgent need to increase the number of telematics companies and at the same time to create favourable conditions for emerging private enterprises that require better knowledge in economics, business, and company management. 
This paper discusses the telematics business and management in Bahrain market, the most important applications of telematics in Bahrain is vehicle telematics application and navigation using PNDs. The paper organized as follows; after the introduction in section one, the importance of telematics and its contribution in economic development is presented in section two; section three will discuss the telematics business in Korea and China; section four is discussing the telematics business in Bahrain Market; after that we are going to present some of the available telematics applications in Bahrain in section five; finally, a conclusion is presented in section six.

\section{Importance of Telematics and Its Contribution in Economic Development}

The expansion of information and communication technologies (ICT) from hardware, software, Internet, telephone, content, information, application, support service [11] and the growth in wireless connectivity has changed the way people live, work, and play. New knowledge and the use of new ICT technologies have resulted in the creation of new products, services, and jobs, some of which were unbelievable only a few decades ago. At the same time, trade agreements and the reduced costs of communications and transportation have increased the flow of capital, goods, services, knowledge and jobs between countries, the result has been significant worldwide economic growth [12]. As a result, it has been noticed that firm's using ICT has faster growth, higher productivity and faster employment growth. Moreover, ICT helped in growing individual economic opportunity and enabled people to enhance their knowledge and skills. Also, it helped individual to use their income more wisely and manage their own businesses efficiently [11].

Telematics is part of Information and communication technologies (ICT) which plays a major role in the economic development of countries. As it has been mentioned in earlier sections that telematics is about the technology of sending, receiving and storing information via telecommunication devices (GSM/GPRS) along with controlling of remote objects/devices. Therefore, telematics has the following main characteristics [10]:

$\checkmark$ Timeliness, by providing users with immediate access to information anytime.

$\checkmark$ Mobility, by providing services anywhere.

$\checkmark$ Individuality, by providing services reflecting the user's geographical location and demand.

$\checkmark$ Convenience, by providing useful information and services.

There are various key players having important role in the Telematics industry which contributes in economic development. They are basically classified into three categories; software, hardware and network related. Among the software related players, there is a player called the "service provider" which provides the users with the Internet or telematics services such as web browsing, vehicle location, e-mailing, and advertising. Another software related player is called "the contents provider" which provides the user with contents and data. Basically, software related providers are operated by automakers, auto dealers, internet service providers, advertisement firms, digital map distribution firms, or several other facilities [13].

Hardware related players are automakers, consumer's electronics firms, communication equipment firms, and in-vehicle device suppliers which provide the car navigation system that is expected to be a communication device for telematics. In addition, vendors of mobile phones and PNDs (Portable Navigation Devices) will have the potential to be hardware related players.

Network related players provide network infrastructure such as mobile communication infrastructure, wireless LAN, and ground station digital TV broadcasting, which are essential technologies for telematics. Telecommunication companies, broadcasting companies, and IT solution vendors which connect telematics to other businesses can be listed as network related players [13].

Therefore, all those players will support in providing the telematics services which indeed will contribute in economic development.

\section{Telematics in Korea and China}

Korea and China have witnessed significant economical development in recent years, mainly as a result of their technological development in the areas of ICT (information and communication technology) and semiconductor technology. In particular, the telematics industry, which incorporates information technology (IT) into automobiles, has received increasing attention by users, however, there are many issues surrounding the telematics industry that need to be addressed both academically because the industry is still in its initial stages of the production life cycle and there remain substantial development gaps between countries. On average, the global telematics industry has grown $37.8 \%$ per year since 2006 , and it is expected to reach USD 119.4 billion. The telematics industry has been providing stakeholders with, new opportunities for developing and strengthening their value chain [10]. 
In Korea, the demand for telematics has been increased by the government, fleet owners and individuals because of the countries' complex road conditions and frequent traffic jams. Based on Korea's world-class, telecommunications infrastructure and mobile communications technology and the technical competitiveness of the automobile industry, the country's telematics market is expected to become an important part of the global telematics industry.

In China the government selected the telematics industry as one of China's three main growth engines and invested more than RMB 10 billion to produce more than 200 million cars with telematics technology by 2020. Since then, many stakeholders, including those in the automobile industry, have regarded the telematics industry as an important symbol of advancement, innovation, and value added and thus, have focused on developing and providing a wide range of telematics products and services. In recent years, Korea and China, taking advantage of their geographical proximity, have engaged in bilateral negotiations and trade to expand their telematics presence.

\section{Telematics Market Development in Bahrain}

In Bahrain the demand for Vehicle Telematics Management Systems (VTMS) has been increasing because fleet owners are looking for reducing their costs, utilize their fleet and maximize productivity. Moreover, due to the big jump in telecommunication infrastructures and mobile communication technology made it easy for businessman (specialized or non-specialized) to enter such market in Bahrain and provide this service.

Vehicle Telematics started in Bahrain in 2006. There were two companies providing this service for fleet owners in public and private sectors. One of those companies started this business by providing full system component (configuration, application, servers, GIS Bahrain map, website hosting and system support) in-house through its humble R\&D section, except the Telematics units was purchased from outside suppliers in US, Korea and China. The other company was dealing with third party outside Bahrain which provides full vehicle Telematics system components with very low cost and low quality. Therefore, this company does not have any team for development; simply buy and sell. Then in 2007 another company joined this market and followed by another company in 2009. After that in 2010 and 2011 another three companies entered the vehicle Telematics business. Finally, in 2012 another five companies added to the list of companies that provide such products and service in Bahrain Market (see Table I and Figure 1).

Table 1. Number of companies that provide Vehicle Telematics products and services in Bahrain since 2006 to 2012

\begin{tabular}{|c|c|}
\hline Year & \# of Companies \\
\hline $\mathbf{2 0 0 6}$ & 2 \\
\hline $\mathbf{2 0 0 7}$ & 3 \\
\hline $\mathbf{2 0 0 8}$ & 3 \\
\hline $\mathbf{2 0 0 9}$ & 4 \\
\hline $\mathbf{2 0 1 0}$ & 5 \\
\hline $\mathbf{2 0 1 1}$ & 7 \\
\hline & 12 \\
\hline
\end{tabular}

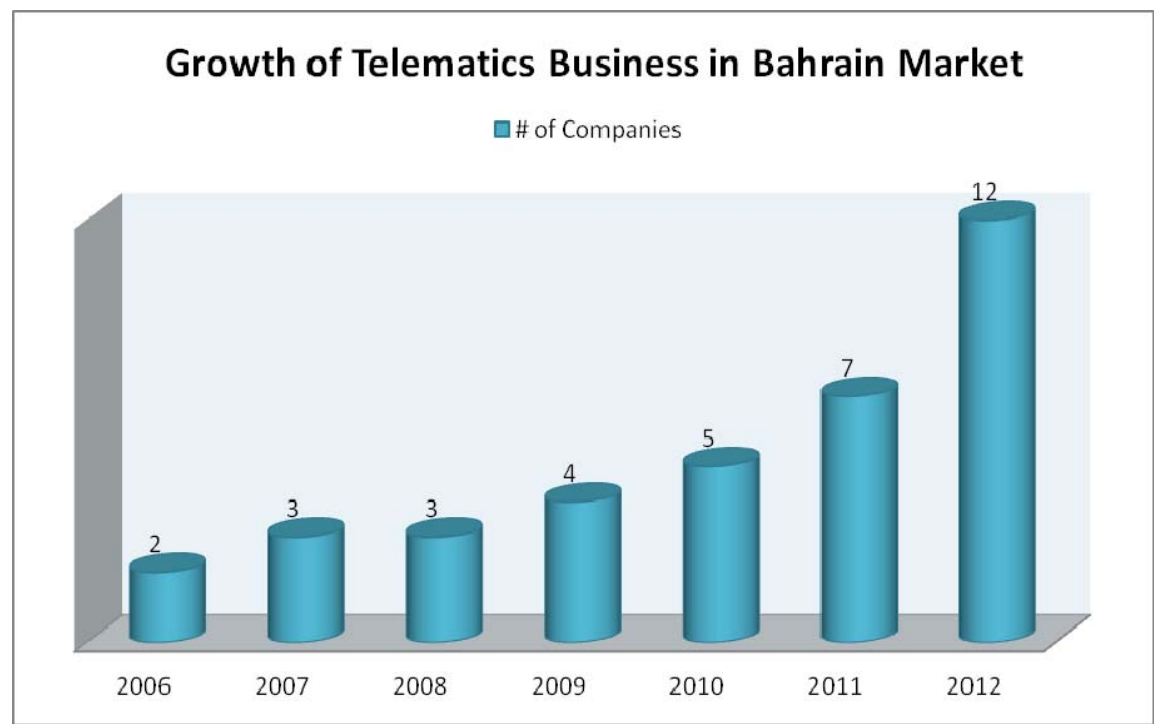

Figure 1. Number of companies that provide Vehicle Telematics products and services in Bahrain since 2006 to 2012 
The following (Table II and Figure 2) demonstrate the growth potential of Bahrain vehicle telematics market and the number of vehicle telematics units mounted so far since 2006 to 2012.

Table 2. Number of vehicles with mounted vehicle telematics system in Bahrain since 2006 to 2012

\begin{tabular}{|l|c|}
\hline Year & \# of Vehicles with Telematics system \\
\hline $\mathbf{2 0 0 6}$ & 500 \\
\hline $\mathbf{2 0 0 7}$ & 1250 \\
\hline $\mathbf{2 0 0 8}$ & 1550 \\
\hline $\mathbf{2 0 0 9}$ & 2000 \\
\hline $\mathbf{2 0 1 0}$ & 2600 \\
\hline $\mathbf{2 0 1 1}$ & 3250 \\
\hline $\mathbf{2 0 1 2}$ & 4750 \\
\hline
\end{tabular}

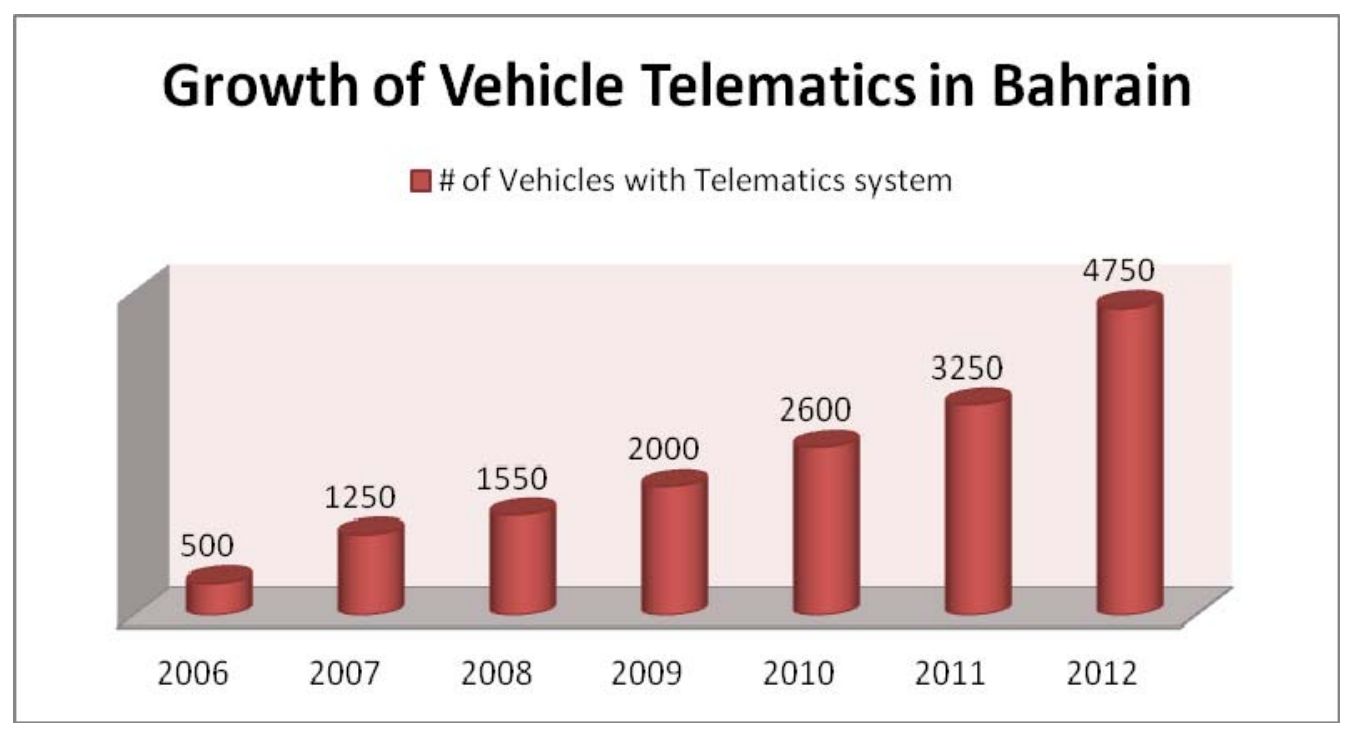

Figure 2. Number of vehicles with mounted vehicle telematics system in Bahrain since 2006 to 2012

It is clear from the earlier graphs and tables that the number of companies entered the market of Telematics in 2012 have increased dramatically along with the number of mounted vehicle telematics units in same year. This big change is due to the demand in modern transportation for vehicle telematics to increase reliability, safety and security of both vehicles and drivers. Moreover, the political situation arise in Bahrain in 2011 has caused to increase the demand of vehicle telematics system too.

As a result of the growth in Bahrain's population and the prosperous economy, the number of registered vehicles in the kingdom has been growing at average rate of $6.7 \%$ between 2005 and 2011; the total number of vehicles on Bahrain roads reached high of over 475 thousand at the end of 2011 (see Table III and Figure 3) [14]. This means that still there is a big potential for the vehicle telematics business to expand more in Bahrain market.

Table 3. Number of Vehicle Registered and in use (2005-2011) [14]

\begin{tabular}{|l|c|c|}
\hline Year & \# of Vehicles Registered & \% of increase \\
\hline $\mathbf{2 0 0 5}$ & 314,033 & 7 \\
\hline $\mathbf{2 0 0 6}$ & 337,545 & 8 \\
\hline $\mathbf{2 0 0 7}$ & 366,732 & 8 \\
\hline $\mathbf{2 0 0 8}$ & 399,546 & 7 \\
\hline $\mathbf{2 0 0 9}$ & 428,957 & 5 \\
\hline $\mathbf{2 0 1 0}$ & 452,222 & 5 \\
\hline $\mathbf{2 0 1 1}$ & 475,150 & \\
\hline
\end{tabular}




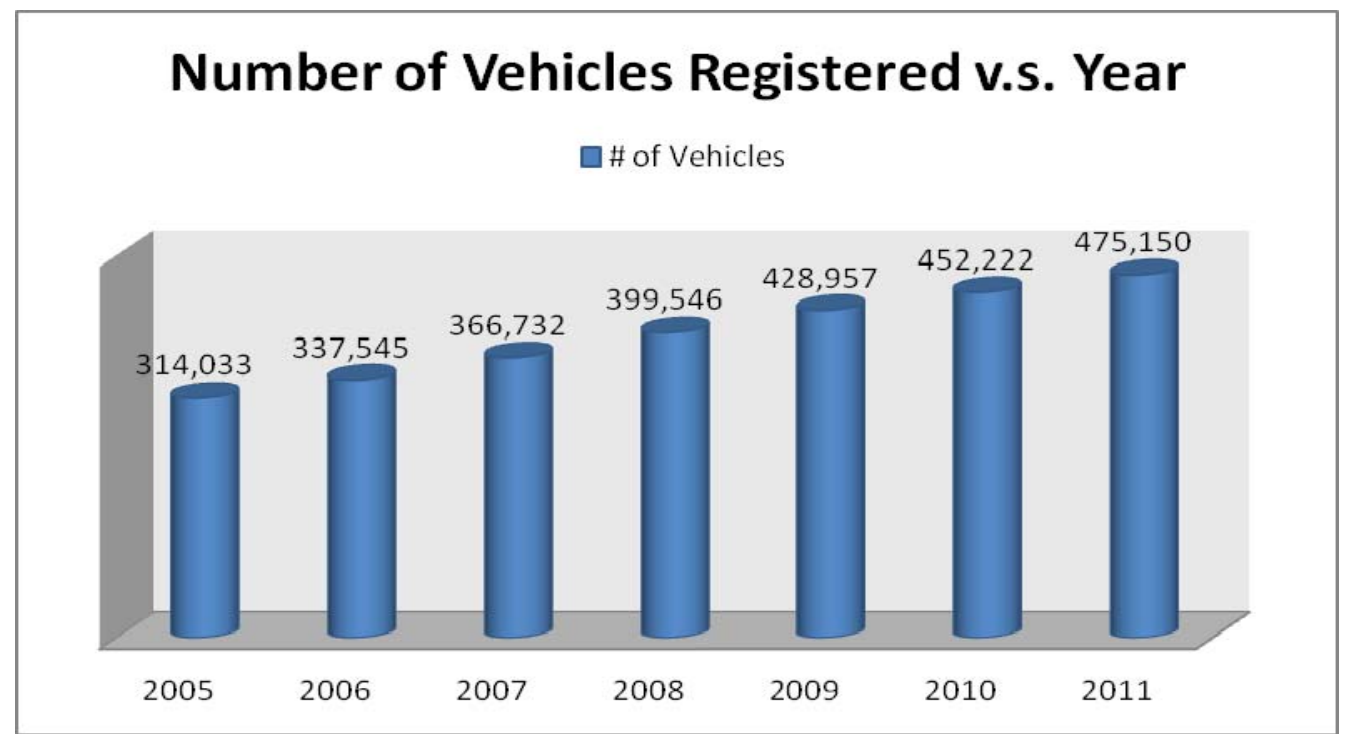

Figure 3. Number of Vehicle Registered and in use (2005-2011) [14]

\section{Available Telematics Applications in Bahrain}

The most important applications of telematics in Bahrain are vehicle telematics application and navigation. Vehicle telematics is a way of monitoring the location, movements, status and behaviour of a vehicle or fleet of vehicles (such as sedan cars, trucks, containers, motorcycles, etc...) remotely to enhance the functionality, productivity and security of both vehicles and drivers [15].

SmartTrack in one of the famous vehicle telematics application that is available in Bahrain. This is the flagship telematics product offered by Spatial Technology Solutions (STS) one of the newly established ICT companies in Bahrain [16]. SmartTrack is a complete web-based fleet tracking and management solution, which comes with a wide array of standard and optional features to suite every customer needs. SmartTrack is built around proven hardware and software technologies from leading H\&S technology providers in the world including Microsoft (for the back-end server), ESRI GIS for the mapping software, and leading GPS engine suppliers. The three main components of SmartTrack are the following:

* Vehicle-mounted tracking unit (VTU): a black box integrating a GPS engine with a GSM/GPRS mobile communicator to communicate with the back-bone servers' platform were the receiver application and databases are hosted.

* SmartTrack fleet Application: a web-based application that offers the users the ability to track their vehicles live, and to obtain historical reports giving details of their vehicles movements and status at any given time, as shown on Figure 4-6.

* SmartTrack Hosting platform: This is the back-bone servers' platform which host the applications and mapping engine of SmartTrack.

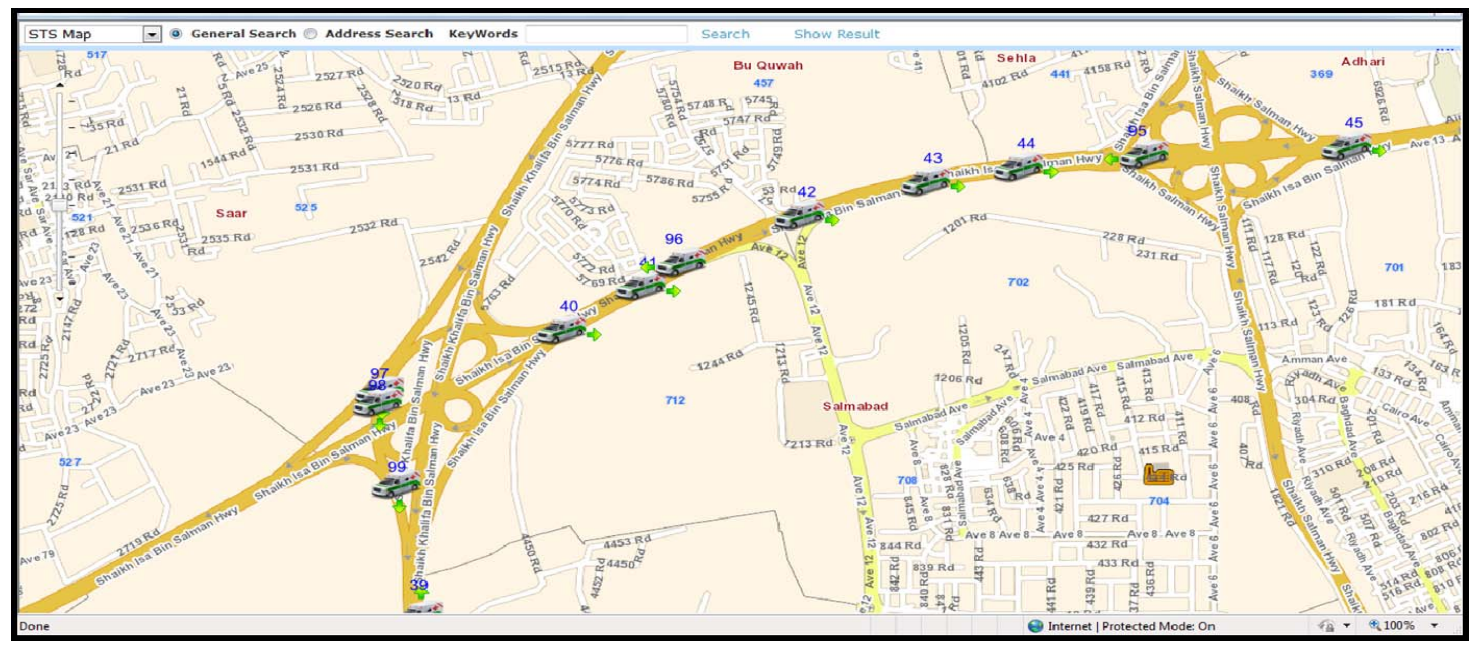

Figure 4. STS Digital Map View of Vehicle Tracking in Bahrain 


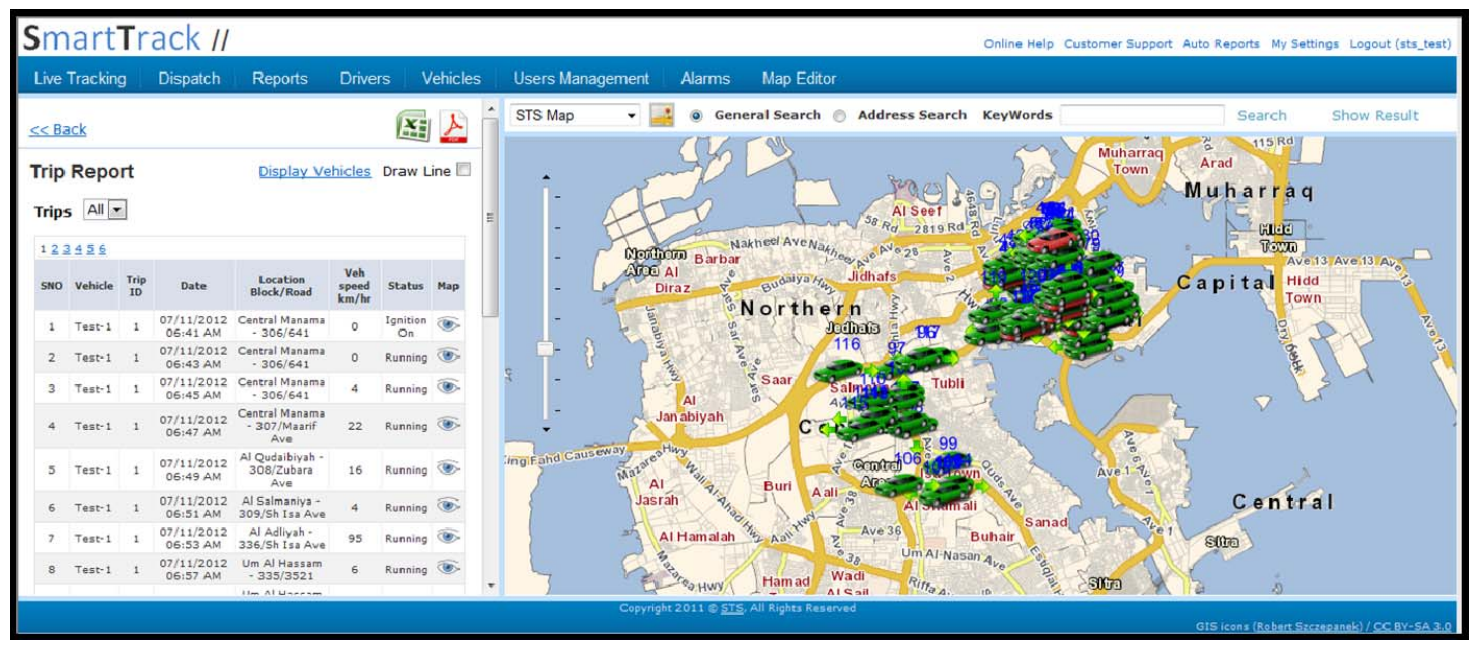

Figure 5. Sample of historical vehicle points (in Trip Report) viewed on STS Bahrain map in SmartTrack website

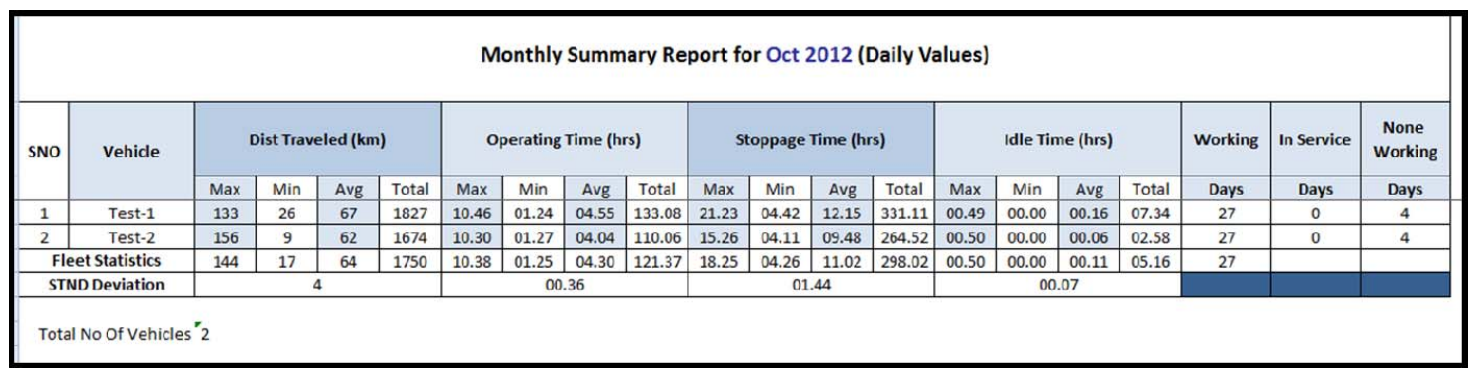

Figure 6. Smaple Monthly Summary Report of Vehicle Telematics (SmartTrack) in Bahrain

Customers using such technology are many and include emergency vehicles (e.g. ambulance, electricity, water and fire brigade), delivery cars, construction vehicles, taxis, waste collection and buses. The benefits realized from using this technology includes the following; improved driver/vehicle management, reduced fuel consumption (hence reduced pollution), reduced maintenance cost, reduced accident \& misuse, and improved customer delivery services and improved fleet efficiency.

Finally, navigation is the second application used as one of the Telematics services provided in Bahrain. Typically, this involves the use of Personal Navigation Devices (PND) also called Portable Navigation Devices which are portable electronic devices which combines a positioning capability (such as Global Positioning Systems (GPS)) and navigation functions is much convenient, safer and reliable solution for drivers to find their destinations without the need of having a paper based maps [17]. All PNDs work essentially the same way. They store map data locally on the device, which must be updated with some frequency (quarterly or annually) and support routing algorithms (the fastest route or the shortest route to destination) [18]. Some newer PNDs provide some real-time weather and traffic data via a data connection over a cellular network [19].

\section{Conclusions}

In this paper we have presented and discussed issues related to telematics business and management in Bahrain market. The paper also discussed telematics in Korea and China, as an example for telematics applications in other countries. As an example of telematics business in Bahrain, the paper discussed the growth of vehicle telematics products and services in Bahrain since 2006 to 2012. The provide table and chart demonstrated the growth potential of Bahrain vehicle telematics market and the number of vehicle telematics units installed during the period of year 2006 to 2012. The charts and tables demonstrated that there is an increase in the use of vehicle telematics products in Bahrain during the last six years, as indicated also by a large increase in the number of service providers during the same period. 


\section{References}

1. Siriginidi Subba Rao. (2009). Achieving millennium development goals: Role of ICTS innovations in India, Telematics and Informatics, 26 127-143.

2. Ming-Chiao Chen, Jiann-Liang Chen, Teng-Wen Chang. (2011). Android/OSGi-based vehicular network management system, Computer Communications, 34 169-183.

3. Laurie, A. (2012). Telematics-The New Auto Insurance, Retrieved September 13, 2012, from www.towerswatson.com/assets/pdf/4125/1101-Telematics-FIN.pdf

4. GPRS Services (2012). Retrieved October 12, 2012, from http://www.koreTelematics.com/m2mtechnologies/gprs.html

5. GPRS: General Packet Radio Service (2012). Retrieved October 12, 2012, from http://www.4gamericas.org/index.cfm?fuseaction=page\&sectionid=243, (12-10-2012)

6. Hossaina, E., Chowb, G., Leungc, Victor C. M., McLeoda, R., Mišic, J., Wongc, Vincent W. S., Yange, O. (2010).Vehicular Telematics over heterogeneous wireless networks: A survey, Computer Communications, ScienceDirect, 33, 775-793.

7. GPS Personal Tracking. (2012). Retrieved October 12, 2012, from http://www.liveviewgps.com/ gps+personal+tracking.html

8. Shirazia, F., Gholamib, R., Higo, D. An. (2009). The impact of information and communication technology (ICT), education and regulation on economic freedom in Islamic Middle Eastern countries, Information \& Management, ScienceDirect, 46, 426-433.

9. Lenflea, Sylvain, Midlerb, Christophe. (2009). The launch of innovative product-related services: Lessons from automotive telematics, Research Policy, 38 156-169.

10. Young-Wook Song, Ji Dae Kim, Liangri Yu, Hyun Kyung Lee, and Hyung Seok Lee. (2012). A Comparative Study of the Telematics Industry in Korea and China, Chungbuk National University, South Korea. Retrieved November 19, 2012, from http://www.arraydev.com/commerce/ jibc/articles.htm

11. Kramer, William J., Jenkins, Beth and Robert S. Katz. (2007). The Role of the Information and Communications Technology Sector in Expanding Economic Opportunity. Harvard: The Fellows of Harvard College.

12. Kozma, Robert B. (November 2005). Education Reform, and Economic Growth. Retrieved December 3, 2012, from ftp://download.intel.co.jp/education/wsis/ICT_Education_Reform_Economic_Growth.pdf

13. Norihito Shimizu. (June 2004). Analysis of Automotive Telematics Industry in Japan, Massachusetts Institute of Technology. Retrieved December 3, 2012, from http://dspace.mit.edu/handle/1721.1/17879

14. Vehicle Registered in Use, New and Cancelled (2004-2011), Table 15.1, Transport and Communications, (2011). Retrieved November 26, 2012, from http://www.cio.gov.bh/CIO_ENG/ SubDetailed.aspx? subcatid $=567$

15. UK Telematics Online. VEHICLE TRACKING \& VEHICLE TELEMATICS explained. Retrieved September 20, 2012, from http://www.uktelematicsonline.co.uk/

16. SmattTrack (Fleet Management System). Retrieved October, 23, 2012, from http://smarttracksts.com/smarttrackv2

17. Dispatch and Navigation Garmin to Contigo. (2011). Retrieved October, 8, 2012, from http://www.gpsdirectonline.com/contactcommerce/images/downloads/Contigo_Dispatch_Nav_Datas heet.pdf

18. Personal Navigation Devices. Retrieved November 24, 2012, from http://www.navipedia.net/ index.php/Personal_Navigation_Devices

19. Personal Navigation Devices. Retrieved November 24, 2012, from http://personalgps.wordpress.com/ applications/personal-navigation-devices/ 